\title{
AS FILHAS NEGRAS DA MÃE AMAZÔNIA EM UM FAZER CIENTÍFICO
}

\author{
Celenita Gualberto Pereira Bernieri \\ Maria das Dores do Rosário Almeida \\ Elivaldo Serrão Custódio
}

Resumo

As mulheres negras ativistas amazônidas têm vivido, nesta década, o momento de maior transformação nas gerações. Embora suas dinâmicas tenham sido fundamentadas por meio de ensinamentos comunitários, desencadearam-se em rumos distintos em diferentes trajetórias de saberes. Alterações que estão relacionadas aos contextos de saberes tradicionais e conhecimentos científicos e à forma que se potencializaram as relações de interculturalidade dessas mulheres. Assim, o objetivo desse artigo é apresentar a visão de duas mulheres negras quilombolas sobre o Programa do Mestrado Profissional em Sustentabilidade junto a Povos e Terras Tradicionais (MESPT), proposto pela Universidade de Brasília (UnB) que, com o apoio do Centro de Desenvolvimento Sustentável (CDS), tem oportunizado estratégias de emancipação para a resistência de determinados povos diante das incertezas da educação pública. Este estudo se materializa apresentando uma organização de ideias a partir da fundamentação teórica bibliográfica, que apoia a abordagem qualitativa dos fatos históricos e sociológicos. Os resultados apontam que essas mulheres negras amazônidas têm um grande potencial na produção de conhecimento científico e cultural.

Palavras-chave: mulheres negras; Amazônia; MESPT.

\section{THE BLACK DAUGHTERS OF AMAZON MO'THER IN A SCIENTIFIC} DOING

\begin{abstract}
In this decade, black women activists from the Amazon have experienced the greatest transformation in generations. Although its dynamics were based on community teachings, they were unleashed in different directions in different knowledge trajectories. Changes that are related to the contexts of traditional knowledge and scientific knowledge and to the way that the intercultural relations of these women were enhanced. Thus, the objective of this article is to present the vision of two black quilombola women about the Professional Master's Program in Sustainability with Traditional Peoples and Lands (MESPT), proposed by the University of Brasilia (UnB), which, with the support of the Centro de Sustainable Development (CDS), has provided opportunities for emancipation strategies for the resistance of certain peoples in the face of uncertainties in public education. This study is materialized by presenting an organization of ideas based on the theoretical bibliographic foundation, which supports the qualitative approach of historical and sociological facts. The results show that these black Amazon women have great potential in the production of scientific and cultural knowledge.
\end{abstract}

Keywords: black women; Amazon; MESPT.

\section{LAS HIJAS NEGRAS DE LA MADRE AMAZONIA EN UNA ACCIÓN CIENTÍFICA}

Resumen

Las mujeres negras activistas en la Amazonía han experimentado, en esta década, el momento de una mayor transformación en las generaciones. Aunque su dinámica se basó en las enseñanzas de la comunidad, se desataron en diferentes direcciones en diferentes trayectorias de conocimiento. Cambios relacionados con los contextos del conocimiento tradicional y el conocimiento científico y con la forma en que se mejoraron las relaciones interculturales de estas mujeres. Por lo tanto, el objetivo de este artículo es presentar la visión 
de dos mujeres negras quilombolas sobre el Programa de Maestría Profesional en Sostenibilidad con Pueblos y Tierras Tradicionales (MESPT), propuesto por la Universidad de Brasilia (UnB), que, con el apoyo del Centro para el Desarrollo Sostenible (CDS), ha proporcionó estrategias de emancipación para la resistencia de ciertos pueblos a las incertidumbres de la educación pública. Este estudio se materializa presentando una organización de ideas basada en la base bibliográfica teórica, que apoya el enfoque cualitativo de los hechos históricos y sociológicos. Los resultados muestran que estas mujeres amazónicas negras tienen un gran potencial en la producción de conocimiento científico y cultural.

Palabras clave: mujeres negras; Amazonas; MESPT.

\section{INTRODUÇÃO}

O presente artigo tem por objetivo apresentar a visão de mulheres negras e quilombolas amazônidas sobre o programa de Mestrado Profissional em Sustentabilidade junto a Povos e Terras Tradicionais (MESPT), proposto pela Universidade de Brasília (UnB) que, com o apoio do Centro de Desenvolvimento Sustentável (CDS), tem oportunizado estratégias de emancipação para a resistência de determinados povos, diante das incertezas da educação pública.

O acesso de mulheres à educação é, sem dúvida, resultado de inúmeras buscas e investimentos em processos de transformação. Perceber a presença de mulheres negras e quilombolas nesse contexto intelectual de extrema disputa - o mestrado - nos leva, espontaneamente, a lembrar que, por muito tempo, as categorias de classe social, raça e gênero foram adotadas teoricamente como filtros de seleção, por um sistema de ensino extremamente racista, sexista e excludente que, conforme Hooks (2015) argumenta, mantinha coletivamente esse grupo numa base inferior e mais distante da formação acadêmica, do que qualquer outro.

Nessa conjuntura, "É essencial para a continuação da luta feminista que as mulheres negras reconheçam o ponto de vista que a nossa marginalidade nos dá [...] para criticar a hegemonia racista, classista e sexista dominante e criar uma contra hegemonia" (HOOKS, 2015, p. 208).

Com o surgimento do MESPT, que constitui uma estrutura investida em ações afirmativas, com a priorização das semelhanças identitárias e contextuais entre os povos de comunidades tradicionais, a contribuição foi dada.

O exemplo é a qualificação de mulheres negras e quilombolas com potencialidade de se relacionarem, desenvolvendo-se sustentavelmente nessa lógica comunitária de ideias que culturalmente os povos tradicionais do Brasil e também do exterior têm mantido, evidenciadas nos diálogos e pesquisas atualmente realizados.

Compreende-se que o objeto desse estudo é pensado a partir da trajetória de vida de pesquisadoras negras - Celenita Laurinda Gualberto Pereira Bernieri e Maria das Dores do Rosário Almeida -, mulheres amazônidas, lajense e macacoariense respectivamente. São ambas ativistas, há alguns anos, de movimentos de mulheres negras e quilombolas, sejam historicamente culturais, sejam ideologicamente políticos. A primeira, filha de Maria Anita Gualberto Pereira, uma mulher professora na Comunidade Quilombola de Lajeado, em Dianópolis / Tocantins (TO); a segunda, filha de Luiza do Rosário Almeida, uma mulher roceira da Vila do Carmo do Macacoari, localizada no município de Itaubal / Amapá (AP), no extremo Norte da Amazônia.

As pesquisadoras foram espontaneamente tomadas pela esperança de viver, na educação presente, melhores momentos, baseados nas lutas e sonhos de suas avós e mães, e, assim, se refletirem, de algum modo, no futuro de suas filhas, enquanto continuar esse legado histórico no Brasil.

Embora as dinâmicas geracionais dessas mulheres tenham sido fundamentadas nos ensinamentos comunitários, através da oralidade e das práticas tradicionais de ensino e aprendizagem, passado um tempo esses conhecimentos estão dispostos em diferentes trajetórias 
de saberes que se cruzaram. Diferentemente das avós que não frequentaram escola, suas mães até acessaram a educação formal, mas que só veio fazer parte de suas vidas na adolescência e (ou) mesmo depois de casadas; as pesquisadoras, filhas dessas mulheres, vêm estudando desde os anos iniciais do ensino fundamental, desencadeando caminhos bem distintos. Uma realidade nunca vista antes, que foi possível em razão de esforços coletivos dos movimentos sociais, ainda que nem todos tenham usufruído dos objetivos já alcançados. Venceram, pois a política de ações afirmativas implicou garantir educação, enquanto direito constitucional, aos reconhecidos grupos étnicoraciais. Mas, segundo Grisa e Caprara (2016), analisar a viabilidade financeira da gestão pública brasileira para garantir o aumento de negros e negras na universidade exige que se considere, nos estudos, os embates na área de política orçamentária, identificando como esta viabiliza, ou não, recursos para que a demanda de movimentos negros por educação se realize efetivamente.

Esse estudo se materializa apresentando uma organização de ideias a partir de três seções. $\mathrm{Na}$ primeira, apresentam-se as potencialidades interculturais identitárias. Em seguida, a interculturalidade e os reencontros no MESPT. Depois, a transdisciplinaridade em 3D: desafios, desconstruções e descobertas. Por fim, tecem-se considerações finais sobre a realidade e os desafios do acesso e permanência dessas duas mulheres negras e quilombolas à educação, suas inserções educacionais desde a infância, ao ensino comunitário, até chegar à educação superior e à pósgraduação.

\section{POTENCIALIDADES INTERCULTURAIS IDENTITÁRIAS}

O MESPT se compreende como um Programa proveniente da UnB, enquanto instituição pública de ensino, na pós-graduação, que qualifica profissionais em Sustentabilidade dos Povos e Terras Tradicionais, assegurando o direito de homens e mulheres consolidarem cientificamente suas identidades e saberes culturais específicos. Contudo, sua identidade se define como uma organização que promove formações transdisciplinares a sujeitos autônomos e resilientes, no compromisso de articular, defender e fortalecer suas práticas comunitárias e territoriais.

Em entrevista concedida ao Afreaka ${ }^{1}$, o escritor e biólogo moçambicano Mia Couto (2013), ao falar de identidade, disse: "Eu nasço dentro de uma nação que está em busca do seu próprio retrato, da sua moldura. Isso faz com que eu perceba que a busca de identidade mesmo sendo falsa e plural, é o que me motiva".

Ainda na mesma entrevista, Mia Couto (2013) diz que: "Não existe uma identidade, mas as pessoas vivem em uma fortaleza". Assim é a identidade do MESPT: plural, na busca de um novo retrato para a UnB, ao se permitir quebrar as muralhas de privilégios de acesso à pós-graduação, ao propor incluir nos processos seletivos de mestrado candidaturas daqueles que sempre foram objetos de estudo, como as mulheres negras.

De início, os povos ali representados por suas lideranças negras, indígenas, quilombolas, ribeirinhas, extrativistas e geraizeiras buscavam nesse espaço dialogar, em busca de reconhecimento, valorização e amplificação das vozes que vinham ecoando há muito tempo, sem serem ouvidas. Foi a acolhida da apresentação dessas duas mulheres (Celenita e Maria das Dores), numa ciranda bem familiar, que se caracterizou como o método para que todos pudessem dar sua contribuição nesse debate colaborativo que, sem pressa para acabar, se instalou no CDS. Como diz Celenita Laurinda Gualberto Pereira Bernieri, "[...] fez do MESPT o coração da UnB, onde pulsa vida e transborda como a fonte de saberes em que bebe o arco-íris".

1 O Afreaka é um projeto de jornalismo independente, design e cultura digital que traz um conteúdo inédito sobre a África a partir da perspectiva da comunicação para o desenvolvimento. Disponível em: http://www.afreaka.com.br/colabore. Acesso em: 17 jun. 2019. 
Tal ponto de vista é justificado por evidências e perspectivas presenciadas por mulheres negras e quilombolas que continuam buscando conhecimentos, pela compreensão de processos históricos e das lutas travadas desde os ancestrais, que deram suas vidas pelo sonho de consolidação de direitos e deveres democraticamente construídos, mas que, por sua vez, hoje, estão sendo desfeitos. O que essas duas mulheres demandam - empoderar-se, provendo mecanismos de informações e estratégias feministas / comunitárias - tem base nas demandas das diversidades contextuais.

Compreendemos que o processo político de crises no Brasil vem se prolongando há vinte anos, e tem mudado com frequência os rumos da educação pública no país. De certo modo, a condição de os povos tradicionais começarem a acessar a pós-graduação em universidades públicas se deu a partir das influências internacionais pós-Durban, que pressionaram o Estado brasileiro para o cumprimento da política de educação gratuita assegurada às esferas socialmente marginalizadas.

Para os afrodescendentes, isso só desencadeou, conforme Heringer (2011) retratou, fatos que marcaram, feliz e dolorosamente, a luta dos movimentos negros iniciada em 2003. Mas, somente em outubro desse mesmo ano, criou-se um Grupo de Trabalho Interministerial (GTI), reunindo onze ministérios, o Conselho Nacional de Educação e a Advocacia-Geral da União, com o objetivo de fazer um levantamento completo de dados sobre desigualdades raciais e étnicas no ensino brasileiro, para, posteriormente, propor uma política de acesso, para afrodescendentes, ao ensino superior.

$\mathrm{O}$ acesso de mulheres negras amazônidas ao MESPT lhes permitiu aproximar-se de concepções e epistemologias, como estratégias para construir o pensamento feminista negro amazônico. Conforme afirma Câmara (2017, p. 27), as epistemologias lançadas pelas feministas negras da Amazônia são estratégias para fazer ressoar suas próprias vozes e serem ouvidas, apoiando-se em novos referenciais, principalmente, fora da Europa. Ainda assim, não é o bastante para a garantia de permanência das mulheres negras no MESPT. Faz-se necessária a concessão de bolsas, para que possam se dedicar à integralidade dos estudos.

Houve avanços, e tudo parecia que se iria consolidar, com as medidas que legitimaram politicamente a autorização de cotas e bolsas de auxílio de permanência nas universidades públicas. Permaneceu-se por acreditar que a educação é o único meio pelo qual condicionaremos nosso povo a transmitir valores e cultura a seus filhos, para construir uma sociedade com dias melhores, às futuras gerações. Reafirmávamo-nos enquanto mulheres cada vez mais feministas, buscando fazer da pauta educação um contínuo processo político.

Para isso, foi preciso, então, que a mulher negra do Amapá e a quilombola do Tocantins deixassem seus territórios em busca desses espaços de formação superior. Ficaram sem o seu chão, ao saírem de suas comunidades. Mas, em saga, ganharam o paraíso, ao se encontrarem entre os demais povos tradicionais sentindo-se, assim, em solo fértil para obterem o título científico de mestras. Título este que já detinham, por serem consolidadas como mulheres negras e quilombolas amazônidas, especialistas, feministas / ativistas e educadoras sociais de seus povos.

\section{INTERCULTURALIDADE E REENCONTROS NO MESPT}

Vistas de longe, as relações entre os povos tradicionais aparentam ser sempre amigáveis, inclusive na forma de se tratarem entre si. $\mathrm{Na}$ Comunidade de Lajeado, no Tocantins, e redondezas, é comum ver os mais velhos contarem aos seus como se dava a convivência entre indígenas e quilombolas. Narrativas que apresentam de formas bem variadas, por serem provenientes de pessoas de contextos diferentes (étnicos e temporais). 
Entre as descobertas, o estudo na pós-graduação nos levou a conhecer muitas coisas da nossa história, que eram ditas superficialmente. Houve, sim, relações, algumas mais próximas, outras nem tanto. A manipulação é uma das mais marcantes e duradouras. Trata-se de um fenômeno tão inescrupuloso, que foi capaz de cegar gerações por longos tempos.

Foi o que se observou numa dessas narrativas da Comunidade Quilombola de Lajeado, em Dianópolis / TO, onde a grande população é negra. Os povos indígenas que restaram das etnias gueguês, assus, acroás, xacriabás e xerentes, segundo o Instituto Brasileiro de Geografia e Estatística (IBGE, 2010), foram todos embora há muitos anos, o que levou a matriarca da Comunidade ter de puxar pela memória ao nos dizer: "[...] olha filha, sobre índios, não sei nada além do que me disseram, porque não os conhecia até pouco tempo. Ainda quando criança, tínhamos muito medo deles, disseram-nos que os índios quando viam crianças negras de cabelos encarapinhados, diziam que aquele era os de 'botar pra dormir', o que queria dizer 'matar". Hoje, entendemos que muito do que se contava não passava de mitologia contada pelo homem branco. E sabemos o quanto isto nos custou.

As ideias de Morgan (2002), como o pioneiro a fazer uso das metáforas para análises, nos ajudarão a ilustrar, metodologicamente, com outras palavras, algumas realidades. Assim como na metáfora do rio, em que o escritor Paulo Coelho (2009) já dizia ser a mais próxima do significado da vida: a vida é como um rio, em que a passagem é certa, porque um rio não deixa de correr. Mas entendemos que as águas que correram, ontem, no Tocantins, jamais correrão, hoje, no Médio Rio Negro. E, assim, podemos afirmar que um rio nunca passa duas vezes pelo mesmo lugar.

O raciocínio se completa ao trazermos a fala de Ilma Neri, indígena piratapuia da região do Médio Rio Negro / Santa Isabel, que diz ter poucos negros naquela região, e que os que existem são aqueles vindos de outras regiões do Brasil. Que ela nunca percebeu qualquer tipo de rejeição ou distinção entre eles. Para além disso, discorreu a indígena piratapuia: "[...] as diferenças começam ao se tratar das diferentes etnias, da cultura, dos pensamentos e dos modos de viver. Digo isso porque teve-se a honra de encontrar, no MESPT, mulheres guerreiras, com outros olhares, pensamentos e histórias". Observa-se que, por maiores que fossem as diferenças, com respeito e valorização de quem tem trajetória ancestral comunitária, permitiu-se que aprendêssemos a nos encontrar, buscando equilíbrio nos pontos interseccionais.

Contudo, as pedras precisam ser contornadas nas relações entre os povos tradicionais no Brasil, pois, evidentemente, a água é mais forte que o granito, mas para que isso seja demonstrado é preciso tempo. E este tempo foi suficiente para entendermos que manobras foram feitas com o intuito de impedir a junção dos povos numa busca coletiva por seus ideais. O melhor, então, é entender por onde se encontra a saída e seguir adiante juntos, como nesta relação que se vê hoje, de encontro de reciprocidade entre mulheres negras, indígenas e quilombolas amazônidas.

É consenso entre as mulheres negras, que a hegemonia racista no espaço universitário contra elas é cada vez mais patente. Uma postura fascista com reproduções racistas expostas abertamente, que mais parece vir em resposta à não aceitação de que essas mulheres têm se conscientizado e atuado em enfrentamento com várias frentes. Hoje, é comum perceber a insistência em colocar as mulheres negras em desvantagem. A recente polêmica em torno da campanha do Ministério da Educação retrata muito bem isso, mostrando estudantes que precisam se resumir a uma simples nota no Sistema de Seleção Unificada (SiSU), para ingressar em universidades particulares, pelo Programa Universidade para Todos (ProUni) e ter acesso ao Fundo de Financiamento ao Estudante do Ensino Superior (Fies).

A fala da campanha se firma em torno da linguagem que adota a sobreposição, trazendo a ideia de justaposição como sinônimo da própria metodologia adotada que, coincidentemente, retrata a realidade da política brasileira de educação para negros, a que muitos não têm acesso e a que outros, não negros, avançam, assumindo seus lugares. Isto se dá, especialmente, no projeto em 
que os investimentos para as instituições particulares superam o que são investidos na universidade pública. Por essa estratégia, mantém-se o público prioritário de fora da política, o que também contribui para o manter marginalizado.

O MESPT mais parece "uma gota no oceano", como um dos poucos Programas de educação pública que tem levado a sério uma proposta de ação afirmativa.

A universidade brasileira, enquanto espaço político, vem desempenhando um importante papel no fortalecimento da teoria feminista. Mas, de que feminismo estamos falando? As intelectuais negras brasileiras vêm estabelecendo críticas acerca da teorização do feminismo brasileiro, entre elas, Carneiro (2003) e Conrado (2012).

Para Carneiro (2003, p. 118), as teorias feministas não dão conta de revelar "[...] as diferentes expressões do feminino construídas em sociedades multirraciais e pluriculturais". Em contraponto a essa visão, a autora concebeu o termo "enegrecendo o feminismo", para traçar a trajetória de mulheres negras no interior do feminismo brasileiro.

Conrado (2012, p. 22) destaca que "a naturalização do olhar eurocêntrico nas epistemologias é o que impede a compreensão dos estudos sobre gênero, ao não se levar em conta o lugar da mulher negra na análise das condições sociais de gênero".

Em nossa visão, as epistemologias de Carneiro (2003) e Conrado (2012) têm influenciado a produção de conhecimento de pesquisadoras da temática do feminismo, que conhecem suas obras a partir do movimento de mulheres negras brasileiras e indígenas, porque elas afirmam que o Brasil é um país multirracial e pluricultural e, logo, existem diferentes feminismos, como o feminismo indígena e o negro.

No entanto, observamos que essas intelectuais negras não estão na bibliografia do MESPT. Dito isso, afirmamos que a universidade, enquanto espaço de produção de conhecimentos, para romper com a hegemonia no pensamento feminista, precisa mudar esse conhecimento e formar pesquisadoras negras, indígenas, retireiras, quilombolas, extrativistas, entre outras, uma vez que somos um país formado por cinco regiões distintas, constituídas de diferentes povos.

Podemos dizer que o nosso grande desafio no MESPT foi o de dialogar com autores muito distantes das nossas realidades de vida e de nossas pesquisas. Para superar isso, além de nos debruçarmos em leituras, nossas estratégias foram de olhar para o MESPT como uma grande cabaça mágica, em que cabe tanto o rigor acadêmico quanto as ficções, as diversidades e o conhecimento tradicional. O produto final, a dissertação, é um parto bem-sucedido, mas a arte de partejar não se encerra com o nascimento, mas sim no partilhar o produto com nossas comunidades. Além disso, o MESPT nos possibilitou sermos ativistas pesquisadoras da Amazônia.

\section{TRANSDISCIPLINARIDADE EM 3D: DESAFIOS, DESCONSTRUÇÕES E DESCOBERTAS}

As dinâmicas adotadas pelo MESPT foram extremamente adequadas e oportunizaram que nos aproximássemos e valorizássemos cada vez mais a diversidade dos povos tradicionais. Em cirandas de diálogos, os pontos de vista eram articulados do chão que pisamos e das vivências cotidianas. Por vezes, estávamos compartilhando as angústias por estarmos longe das famílias, a saudade dos parentes, as missões do trabalho e as ideias para os projetos. E, nas diversas conversas, foram surgindo estratégias que vão além do debruçar-se em leituras e de olhar para o MESPT, como dito anteriormente, como uma grande cabaça mágica, em que cabe tanto o rigor acadêmico quanto as ficções, as diversidades e o conhecimento tradicional.

Assim, observa-se estar havendo uma intervenção positiva nesse rígido espaço acadêmico. Sob a hipótese de que os povos de comunidades tradicionais adotariam a transdisciplinaridade como um processo decolonial, numa perspectiva emancipatória de investimentos políticos e 
epistêmicos, as mulheres negras quilombolas e indígenas se declararam feministas piratapuias, laurindas e fulanas que, por sua vez, são amazônidas que estiveram no MESPT, podendo buscar novos conhecimentos, sendo capazes de conviver entre outros povos, ao tempo em que buscaram conhecer esse mundo dos brancos, que era o que mais parecia a UnB.

Foi um encontro colorido e feliz, propício para se fazer amizades inesquecíveis e irmandades duradouras que, baseadas numa relação de conhecimentos, vivências e diferentes histórias, nos inspiram a seguir lutando e referenciar nossa capacidade de reconhecer, umas nas outras, os povos tradicionais brasileiros. E, para além, um despertar de consciências, para a valorização das boas lembranças e de importantes experiências que podemos narrar acerca desse verdadeiro momento histórico de conhecimentos, forjados no meio científico, em que juntas aprendemos a valorizar, ainda mais, nossas ciências e nossos saberes epistêmicos que, hoje, por nós mesmas, serão partilhados ao mundo.

Parece-nos que a ausência de métodos e epistemologias específicas dos povos tradicionais é hegemônica na academia, com suas disciplinas conservadoras, o que é oposto e contraditório aos estudos nas comunidades e (ou) espaços transdisciplinares decoloniais. Bastou um curso interdisciplinar para presenciarmos a capacidade emancipatória dos povos no que tange a poder, ser e conhecer.

Diante desse contexto, com a dissertação de mestrado (Re)construindo caminhos e histórias de vida de mulheres negras da Vila do Carmo do Macacoari - Amapá, a partir de narrativas de mulheres negras, Almeida (2018) concebeu o método criativo de Resgate da canoa e a teoria do conhecimento de que, mulheres negras, estão presentes na Vila do Carmo do Macacoari desde o final do século XIX, quando havia duas categorias de mulheres negras pioneiras: as negras de posse, criadoras de gado; e as negras sem posse, as roceiras. Então, pôde-se identificar, nesse território, duas formas de poder e liderança de mulheres negras amazônidas.

A primeira, através das posses herdadas: quando os homens morriam (pai e maridos), as criadoras de gado se tornavam posseiras das terras da comunidade por mais de cinquenta anos (1926 a 1978). ${ }^{3}$

A segunda, pelas roceiras, sem posses, também lideranças negras femininas muito consideradas, pois os dons de suas mãos thes davam poder e certa hierarquia, exercendo outras funções como: parteiras, rezadeiras, curandeiras, raizeiras, extrativistas, artesãs da Amazônia (tecedeiras de fibras ${ }^{4}$ e louceiras).

Mesmo com as diferenças sociais existentes entre elas, juntas, essas mulheres constituíram uma rede estratégica para a manutenção e a resistência no território, por meio dos usos da mata, do rio, do campo, dos quintais e da solidariedade, o que chamamos de feminismo comunitário, com base na concepção de Paredes (2017, p. 3), que afirma: "[...] decimos comprensión en el sentido de abarcar nuestras luchas y las luchas de otras mujeres"

Para nós, intelectuais negras amazônidas, assim como mostra a autora, criar conceitos próprios, a partir de nossas próprias experiências comunitárias, e escrever - isto é, romper o silêncio - nos tira do lugar de objeto, nos transforma em sujeitos que se constroem em seus

\footnotetext{
2 "Resgate da canoa é uma metáfora, uma simbologia para retratar as mulheres negras ribeirinhas macacoarienses e suas sabedorias, neste caso, aqui, representadas pelas griôs macacoarienses, até então, ninguém havia ido a seu encontro para escutar suas experiências, assim como canoas que ficam à deriva no rio, elas estavam cheias de preciosidades à espera de alguém para resgatá-las.” (ALMEIDA, 2018).

${ }^{3}$ Elas concediam o direito de moradia, e não de propriedade a quem pedia para morar.

${ }^{4}$ Produziam, com fibras e talas de palmeiras, tipitis, abanos, paneiros, redes, rendas, entre outros objetos.

${ }^{5}$ No sentido de visibilizar e manter vivas as lutas de suas ancestrais bolivianas contra as diferentes formas de opressão vividas no passado, em territórios.
} 
próprios termos (KILOMBA, 2013). Ou seja, quebra velhos paradigmas: do colonizador e do colonizado e da fronteira do pensamento que ignora outras formas.

Em outra dissertação de mestrado - Desacanhar da mulher quilombola: emancipacãa intergeracional no jeito sustância das "Laurindas" e "Toaquinas" no Sudeste do Tocantins —, Bernieri (2019) dá vOz e visibilidade à emancipação das mulheres quilombolas, ao apresentar as análises de evidências empíricas, legitimando o modo como resistem reflexos dessa comum história resultante da diáspora que se deu no contexto do novo estado do Tocantins, com antigas práticas de um sistema coronelista, assim também configurado na constituição dos municípios de Dianópolis e Porto Alegre do Tocantins e, consequentemente, nas Comunidades de Lajeado e São Joaquim.

A dissertação de Bernieri (2019), a partir das memórias e narrativas orais de 30 mulheres quilombolas e observando as formas sociais e as estratégias que se correspondem, discute a necessidade de valorizar os saberes ancestrais, os valores culturais e os conhecimentos tradicionais. Visibiliza, assim, mulheres negras enquanto afrodescendentes remanescentes em quilombos e estabelece desafios e perspectivas para o feminismo, adotando nomenclatura para o movimento quilombolista identitário das mulheres: Laurindas e Joaquinas. Mulheres estas que — para além do seu lugar - no contexto territorial, buscam romper com os estereótipos e a racionalidade universalizante estabelecidos. Num exercício herdado das mais velhas gerações pelas mais novas, sugere o Desacanhar por demais espaços.

Mesmo ao encontrar uma existência de opressões interseccionais como fator estruturante de nossas vidas, em termos gerais a pesquisa atesta a hipótese de que as mulheres quilombolas se emanciparam em razão dos processos educacionais, por espontaneamente desenvolverem características de um perfil desacanhado, capaz de produzir e manter viva a prática de ensino comunitário, oral e prática, que na dissertação é reconhecida como Oralidade dos Sentidos - Método de Ensino e Aprendizagem que, fundamentalmente, se estabelece durante os estudos como Metodologia de Pesquisa comunitária. Essa Metodologia tem-se apropriado e multiplicado conscientemente as ciências comunitárias, oportunizando evidenciá-las pela adoção das práticas sociais, ao constituir o Território Humano nelas mesmas.

Percebe-se, a partir dos resultados dessas duas dissertações ora analisadas - com caráter de transformação social de suas realidades locais, tendo como beneficiados os moradores da comunidade - que estas não devem ser apenas um protocolo do MESPT para alimentar o repositório da Biblioteca Central da UnB. As dissertações precisam, acima de tudo, chegar às secretarias municipais de educação, às escolas e às comunidades em geral para serem utilizadas como subsídio, geração de novas pesquisas e / ou apoio para a produção de materiais de suporte didático às escolas quilombolas, tão invisibilizadas no processo educacional do país, como mostram as pesquisas de Custódio e Foster (2019).

Portanto, organismos que promovam a emancipação de pensamentos, como as universidades brasileiras, devem respeitar, no sentido de acolher, os conhecimentos das diferentes culturas, suas diferenças. No entanto, isso somente poderá ser feito se locais de decisão forem ocupados por pessoas que tenham sensibilidade e respeitem a multiculturalidade brasileira, numa conexão real com todos.

\section{CONSIDERAÇÕES FINAIS}

Desde muito tempo, pessoas negras / não brancas acadêmicas e escritoras têm falado e produzido conhecimento independentemente, mas, assim como são grupos cujo poder é desigual, também têm acesso desigual aos recursos necessários para projetar suas próprias vozes (COLLINS, 2000). 
Portanto, chama-se atenção para uma epistemologia que inclua a subjetividade e o pessoal como parte do discurso acadêmico, para que possamos, todos juntos, falar de um espaço, de um lugar e de um tempo específico, de uma realidade e de uma história específicas (HALL, 1990), em contraposição ao cientificismo acadêmico, em que a nossa prerrogativa de falar é reduzida, por uma posição de objetificação, subordinada a estereótipos que muito nos limitam acessar e permanecer.

Prova-se, portanto, que essas mulheres são capazes de produzir o científico, e, agora, o seguinte desafio está em fazer transmitir esses conhecimentos a um grande número de pessoas, podendo influenciá-las a serem, também, sujeitos conhecedores e politicamente multiplicadores para a constituição protagonista de um espaço epistemologicamente sólido.

\section{REFERÊNCIAS}

ALMEIDA, Maria das Dores do Rosário. (Re)construindo caminhos e histórias de mulheres negras da Vila do Carmo do Macacoari - Amapá. 2018. Dissertação (Mestrado em Desenvolvimento Sustentável junto aos Povos e Terras Tradicionais) - Centro de Desenvolvimento Sustentável, Universidade de Brasília (UnB), Brasília, 2018. Disponível em: http://repositorio.unb.br/handle/10482/34042. Acesso em: 26 mar. 2019.

BRASIL. Decreto n. 6.040, de 7 de fevereiro de 2007. Institui a Política Nacional de Desenvolvimento Sustentável dos Povos e Comunidades Tradicionais. Diário Oficial da União: seção 1, Brasília, DF, p. 316, 8 fev. 2007. Disponível em: http://www2.camara.leg.br/legin/fed/decret/2007/decreto-6040-7-fevereiro-2007-550693publicacaooriginal-66733-pe.html. Acesso em: 19 jun. 2019.

BRASIL. Instituto Brasileiro de Geografia e Estatística (IBGE). Perfil dos municípios brasileiros: população do município de Dianópolis, estimada para 2015. IBGE, 2010. Disponível em: https://cidades.ibge.gov.br/brasil/to/dianopolis. Acesso em: 18 jun. 2019.

BERNIERI, Celenita Gualberto Pereira. Desacanhar da mulher quilombola: emancipação intergeracional no jeito sustância das "Laurindas" e "Joaquinas" no Sudeste do Tocantins. Dissertação (Mestrado em Desenvolvimento Sustentável junto aos Povos e Terras Tradicionais) - Centro de Desenvolvimento Sustentável, Universidade de Brasília (UnB), Brasília, 2019.

CÂMARA, Flávia Danielle da Silva. Mulheres negras amazônidas frente à cidade morena: o lugar da Psicologia, os territórios de resistência. 2017. Dissertação (Mestrado) - Programa de PósGraduação em Psicologia (PPGP), Instituto de Filosofia e Ciências Humanas, Universidade Federal do Pará, Belém, 2017. Disponível em: ppgp.propesp.ufpa.br/ARQUIVOS/.../Dissertação\%20Flavia\%20Câmara \%202017.pdf. Acesso em: 25 maio 2018.

CARNEIRO, Sueli. Mulheres em movimento. Estudos Avançados, São Paulo, v. 17, n. 49, set./dec. 2003. Disponível em: http://www.scielo.br/scielo.php?script=sci arttext\&pid=S010340142003000300008. Acesso em: 18 jun. 2019.

COELHO, Paulo. Entendendo o rio. G1, 15 abr. 2009. Disponível em: http://g1.globo.com/platb/paulocoelho/2009/04/15/entendendo-o-rio. Acesso em: 18 jun. 2019.

COLLINS, Patrícia Hill. Pensamento feminista negro: conhecimento, consciência e a política de empoderamento. Nova York: Routledge, 2000.

CONRADO, Mônica Prates. O protagonismo de mulheres negras. In: CONRADO, Mônica Prates et al. Interseções entre raça, gênero, sexualidade, meio ambiente e políticas públicas. Belém: Grupo Nós Mulheres, 2012, p. 22-27. 
COUTO, Mia. Em busca das identidades plurais. [Entrevista cedida a] Flora Pereira e Natan de Aquino. Outras Palavras, Poéticas, 28 maio 2013. Disponível em: http://www.outraspalavras.net/2013/05/28/mia-couto-em-busca-das-identidades-plurais. Acesso em: 17 jun. 2019.

CUSTODIO, Elivaldo Serrão; FOSTER, Eugénia da Luz Silva. Educação escolar quilombola no Brasil: uma análise sobre os materiais didáticos produzidos pelos sistemas estaduais de ensino. Educ. rev. [online]. 2019, v. 35, n. 74, p. 193-211. https://doi.org/10.1590/0104-4060.62715. Disponível em: http://www.scielo.br/pdf/er/v35n74/0104-4060-er-35-74-193.pdf. Acesso em: 19 jan. 2020.

GRISA, Gregório Durlo; CAPRARA, Bernardo Mattes. As políticas de ações afirmativas no ensino superior sob a ótica dos gestores: o caso da Universidade Federal do Rio Grande do Sul. Ciências Sociais Unisinos, São Leopoldo, v. 52, n. 2, p. 172-181, maio/ago. 2016.

HALL, Stuart. Da diáspora: identidades e mediações culturais. Belo Horizonte: Ed. UFMG, 2006.

HERINGER, Rosana. Promoção da igualdade racial no Brasil: um objetivo democrático. Tempo e Presença, n. 330, ano 25, p. 285-311, 2011.

HOOKS, Bell. Mulheres negras: moldando a teoria feminista. Revista Brasileira de Ciência Politica, n. 16, p. 193-210, 2015. Disponível em: http://www.scielo.br/scielo.php?script=sci arttext\&pid=S010333522015000200193\&lng=en\&n $\underline{\mathrm{rm}=\text { iso. }}$. Acesso em: 2 maio 2019.

KILOMBA, Grada. Tradução: Quem pode falar? (Grada Kilomba). Preta, Nerd \& Burning Hell, 12 jan. 2016. Disponível em: http://www.pretaenerd.com.br/2016/01/traducao-quem-pode-falargrada-kilomba.html. Acesso em: 18 maio 2019.

MORGAN, Gareth. Imagens da organização: edição executiva. Tradução de Geni G. Goldschmidt. 2. ed. São Paulo: Atlas, 2002.2 Disponível em: http://www.gbic.com.br/ibes2k9si/1\%BA\%20Semestre/livros/Projeto\%20Livro $\% 20 \mathrm{Adm} \% 20 \mathrm{I}$ magens $\% 20 \mathrm{da} \% 20$ Organizao.pdf. Acesso em: 18 maio 2019.

PAREDES, Julieta. El feminismo comunitário: la creación de un pensamiento propio. Revista Corpus: Archivos virtuales de la alteridad. v. 7, n. 1, enero/junio 2017. p. 1-10.

Submetido em marco de 2020. Aprovado em abril de 2020.

\section{Informações do(as) autor(as)}

Celenita Gualberto Pereira Bernieri

Administradora pública e gestora educacional da Secretaria Municipal de Educação de Dianópolis / TO. Membro ativista e coordenadora da Mulher Quilombola na Coordenação Estadual das Comunidades Quilombolas do Tocantins (COEQTO). Membro ativista e presidenta da Articulação Negra e Quilombola/Alagbara do Tocantins / Brasil.

E-mail: celegpb@hotmail.com

ORCID: http://orcid.org/0000-0001-6437-1538

Link Lattes: http://lattes.cnpq.br/5031951627774896 
Maria das Dores do Rosário Almeida

Militante do Movimento de Mulheres Negras Brasileiras (AMNB). Ambientalista. Co-fundadora do Instituto de Mulheres Negras do Amapá (IMENA) e Rede Fulanas - Negras da Amazônia Brasileira (NAB)

E-mail: mulheresdoigarape@gmail.com

ORCID: http://orcid.org/0000-0002-9994-7952

Link Lattes: http://lattes.cnpq.br/5031951627774896

Elivaldo Serrão Custódio

Professor Permanente do Programa de Pós-Graduação em Educação (PPGED) da Universidade Federal do Amapá (UNIFAP)

E-mail: elivaldo.pa@hotmail.com

ORCID: http://orcid.org/0000-0002-2947-5347

Link Lattes: http://lattes.cnpq.br/8819683729192070 